\title{
A relação familiar com pessoas que possuem transtorno afetivo bipolar
}

Family relationships with people who have bipolar affective disorder

La relación familiar con personas que tienen trastorno afectivo bipolar

\section{Raíssa Ottes Vasconcelos ${ }^{\mathrm{I}}$, Marlene Gomes Terra ${ }^{\mathrm{II}}$, Mariane da Silva Xavier Botega ${ }^{\mathrm{III}}$, Keity Laís Siepmann Soccol ${ }^{\text {IV }}$, Nara Marilene Oliveira Girardon-Perliniv ${ }^{\text {, Cristiane Trivisiol Arnemann }}{ }^{\mathrm{VI}}$}

Resumo: Objetivo: conhecer a perspectiva de familiares acerca da relação com pessoas que possuem transtorno afetivo bipolar. Método: estudo qualitativo, realizado com sete familiares. Os dados foram coletados por meio de entrevista, em março e abril de 2014 e analisados conforme análise de conteúdo. Resultados: a relação está pautada no modo com que a família organiza a rede de apoio entre seus membros e os desafios no cotidiano das relações familiares. Entre os desafios, encontram-se as alterações de humor, a sobrecarga emocional, física e financeira, a dificuldade na adesão ao uso de psicofármacos e a não aceitação do diagnóstico. Considerações finais: é importante acolher e proporcionar momentos de escuta aos familiares nos serviços de saúde, para que seja possível compreender as suas necessidades e implementar estratégias assertivas de melhoria da atenção pela equipe de saúde.

Descritores: Família; Relações familiares; Transtorno bipolar; Saúde mental; Enfermagem

Abstract: Objective: to know the perspective of family members about the relationship with people who have bipolar affective disorder. Method: qualitative study carried out with seven family members. Data were collected through interviews in March and April 2014 and analyzed according to content analysis. Results: the relationship is based on the way in which the family organizes the support network between its members and the challenges in everyday family relationships. Among the challenges are mood changes, emotional, physical and financial overload, difficulty in adhering to the use of psychiatric drugs, and non-acceptance of the diagnosis. Final considerations: it is

\footnotetext{
${ }^{\mathrm{I}}$ Enfermeira. Mestra em enfermagem. Doutoranda em Gerenciamento em Enfermagem. Universidade de São Paulo, São Paulo, SP, Brasil. Email: raissa_07@msn.com ORCID: https://orcid.org/0000-0002-6526-2197

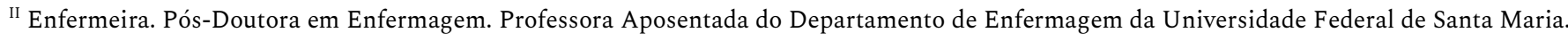
Santa Maria, RS, Brasil. E-mail: martesm@hotmail.com.br ORCID: https://orcid.org/0000-0001-9402-561X

III Enfermeira. Mestra em Enfermagem. Doutoranda do Programa de Pós-graduação em Enfermagem da Universidade Federal do Rio Grande do Sul. Pesquisadora do Grupo de Estudos em Pesquisa em Enfermagem Psiquiátrica e saúde Mental (GEPESM). Santa Maria, Rio Grande do Sul, Brasil. E-mail: marianesxavier@yahoo.com.br ORCID: https://orcid.org/0000-0003-1176-2812

IV Enfermeira. Doutora em Enfermagem. Professora do curso de enfermagem da Universidade Franciscana. Santa Maria, Rio Grande do Sul, Brasil. E-mail: keitylais@hotmail.com ORCID: https://orcid.org/0000-0002-7071-3124

v Enfermeira. Pós-Doutora em Enfermagem. Professora do Departamento de Enfermagem. UfSM. Santa Maria, RS, Brasil. Email: nara.girardon@gmail.com ORCID: https://orcid.org/0000-0002-3604-2507

VI Enfermeira. Pós-Doutora em Enfermagem. Professora do Colégio Politécnico. UfSM. Santa Maria, RS, Brasil. Email: cris.trivisiol@gmail.com.br ORCID: https://orcid.org/0000-0003-2684-3068
} 
important to embrace and provide moments of listening to family members in health services so as to understand their needs and implement assertive strategies to improve the care provided by the health team.

Descriptors: Family; Family relationships; Bipolar disorder; Mental health; Nursing

Resumen: Objetivo: conocer la perspectiva de parientes sobre la relación con las personas que tienen trastorno afectivo bipolar. Método: estudio cualitativo, llevado a cabo con siete parientes. Los datos se recopilaron mediante entrevista, en marzo y abril de 2014, y se analizaron según el análisis de contenido. Resultados: la relación se basa en la forma en que la familia organiza la red de apoyo entre sus miembros y los retos en el cotidiano de las relaciones familiares. Entre los retos, se encuentran los cambios de humor, la sobrecarga emocional, física y financiera, la dificultad para adherirse al uso de psicofármacos y la no aceptación del diagnóstico. Consideraciones finales: es importante acoger y brindar momentos de escucha a los parientes en los servicios de salud, para que sea posible comprender sus necesidades e implementar estrategias asertivas para mejorar la atención del equipo de salud.

Descriptores: Familia; Relaciones familiares; Trastorno bipolar; Salud mental; Enfermería

\section{Introdução}

A reforma psiquiátrica brasileira foi um movimento inspirado na psiquiatria democrática italiana, que teve por objetivo a desconstrução de uma realidade baseada na perspectiva manicomial por meio da desinstitucionalização. Assim, a desinstitucionalização é vista como uma desconstrução de saberes e práticas psiquiátricas, na qual se passou a valorizar a produção da vida para os sujeitos em diferentes espaços sociais. ${ }^{1}$ Ressalta-se que, por meio da reforma psiquiátrica as pessoas que possuíam transtornos mentais tiveram a garantia de seus direitos e foram sendo gradativamente reinseridas nas famílias e na sociedade.

Dentre os transtornos mentais que acometem a população tem-se o Transtorno Afetivo Bipolar (TAB), que causa alterações psicológicas e sociais. No que tange às alterações sociais, estão as dificuldades pessoais, familiares e sociais. Esse transtorno está relacionado à incidência de recaída e pode tornar as pessoas incapazes, por conviverem com barreiras, perdas e limitações nas diferentes esferas da vida cotidiana. ${ }^{2}$

O TAB envolve o humor e afeta pessoas de ambos os sexos, com idade média de trinta anos, podendo ocorrer em dois polos, mania e/ou depressão. As causas desse transtorno podem 
3 | Vasconcelos RO, Terra MG, Botega MSX, Soccol KLS, Girardon-Perlini NMO, Arnemann CT

estar relacionadas à hereditariedade e a situações estressantes. A pessoa acometida sofre mudanças constantes de humor e esta situação pode gerar sofrimento para a pessoa, bem como, para a família e a comunidade. ${ }^{3}$

A presença de uma pessoa com TAB na família altera a sua dinâmica e o modo como ocorrem as relações intrafamiliares, gerando desgaste e demandando compreensão diante de comportamentos não habituais apresentados pela pessoa que o possui. Dentre os integrantes da família, destaca-se o familiar cuidador, que por ser quem assume a maior responsabilidade no cotidiano de cuidado, pode, na existência do dever atribuído, apresentar esgotamento e sofrimento diante da gama de sentimentos com os quais necessita lidar. ${ }^{4}$

A saúde mental se constrói a partir da interação e do protagonismo das pessoas envolvidas, assumindo que os familiares são fundamentais na construção do cuidado psicossocial. Escutá-los e valorizar seus saberes e entendimentos, conhecer sobre as relações familiares com pessoas que possuem o TAB, pode ser um caminho para o aperfeiçoamento do trabalho com as famílias nesse campo. ${ }^{5}$

Nesse sentido, considera-se importante compreender como ocorre a relação familiar com a pessoa que possui $\mathrm{TAB}$, pois por meio dessa compreensão será possível refletir sobre as necessidades das famílias e as mudanças que são imprescindíveis nos serviços de saúde, tendo um olhar holístico, colocando em evidência a família.

Diante do exposto, este estudo teve como questão de pesquisa: como ocorre a relação familiar com pessoas que possuem transtorno afetivo bipolar na perspectiva de familiares? E, como objetivo: conhecer a perspectiva de familiares acerca da relação com pessoas que possuem transtorno afetivo bipolar. 
A relação familiar com pessoas que possuem transtorno afetivo bipolar $\mid 4$

\section{Método}

Estudo qualitativo, exploratório e descritivo, realizado em uma Associação de apoio a pessoas com TAB, familiares e amigos, vinculada a um Hospital Universitário do interior do estado do Rio Grande do Sul, Brasil, que presta atendimento pelo Sistema Único de Saúde (SUS). Trata-se de uma Associação sem fins lucrativos, que oferta uma abordagem terapêutica baseada no paradigma psicossocial, ou seja, o cuidado centrado nas pessoas, que aponta para as dimensões singulares do viver humano, valoriza os aspectos subjetivos e objetivos e considera as dimensões biológica, cultural e social. ${ }^{6}$ A escolha deste cenário ocorreu por ser nas Associações que os familiares encontram a cooperação e o apoio necessários para a convivência e o cuidado às pessoas com transtornos mentais.

Para participação no estudo, adotou-se como critério de inclusão: ser familiar maior de 18 anos de pessoas com TAB, sócio da Associação de apoio a pessoas com TAB, familiares e amigos. Sete familiares aceitaram participar do estudo, apresentando faixa etária de 20 a 61 anos e os seguintes graus de parentesco: irmã, tia, filho(a), mãe e prima. Para garantir o sigilo e confidencialidade dos familiares, optou-se pela utilização da letra 'F' (Familiar), seguida de algarismo numérico (F1, F2..., F7).

A coleta de dados ocorreu entre os meses de março a abril de 2014, por meio de entrevista aberta com cada familiar participante. Para tanto, foi realizada a seguinte questão: como ocorre a relação familiar com o(a) (nome do membro da família com diagnóstico de TAB)? Algumas entrevistas ocorreram em uma sala reservada no Hospital Universitário e outras no domicílio, previamente agendadas, conforme a disponibilidade dos familiares. E, foram gravadas em aparelho de áudio. O tempo para cada entrevista não foi delimitado, no entanto, a média de duração foi de 50 minutos. O encerramento das entrevistas ocorreu por saturação teórica, ou 
5 | Vasconcelos RO, Terra MG, Botega MSX, Soccol KLS, Girardon-Perlini NMO, Arnemann CT

seja, interrompeu-se quando não houve acréscimo de novas informações pertinentes para fundamentar a teorização almejada. ${ }^{7}$

A análise dos dados foi conforme a Análise de Conteúdo, seguindo suas três etapas: préanálise, exploração do material e tratamento dos resultados, inferência e interpretação. Primeiramente, com o auxílio do Software Atlas Ti 7.0, foram realizadas as primeiras inferências às transcrições das falas de cada participante. Após, foram tratados os dados brutos, destacando os pontos de semelhança e diferença presentes no conteúdo. Os resultados foram reunidos em categorias e relacionados com literatura pertinente, a fim de que a relação familiar com a pessoa com TAB na perspectiva dos familiares fosse compreendida. ${ }^{8}$

O estudo atendeu às exigências éticas presentes na Resolução № 466/2012 do Conselho Nacional de Saúde, sendo inicialmente apresentado a Diretoria da referida Associação, a qual concedeu a carta de autorização. Foi aprovado pelo Comitê de Ética em Pesquisa com seres humanos da Universidade Federal de Santa Maria sob Parecer № 460.037, de 18 de novembro de 2013 e CAEE № 23017413.1.0000.5346. Aos familiares, foi propiciado o anonimato mediante a leitura e assinatura do Termo de Consentimento Livre e Esclarecido em duas vias, permanecendo uma com o participante e outra com o pesquisador.

\section{Resultados}

Da análise das entrevistas emergiram duas categorias: Apoio da família como facilitador da relação familiar, e Ser familiar de pessoa com transtorno afetivo bipolar: desafios no cotidiano das relações.

Apoio da família como facilitador da relação familiar 
A relação familiar com pessoas que possuem transtorno afetivo bipolar $\mid 6$

Para os familiares, a fonte primária de apoio à pessoa que possui TAB é a própria família. Nesse sentido, os familiares consideram o apoio da família como sendo fundamental. No entanto, reconhecem que alguns membros do núcleo familiar não sabem como apoiar e acolher a pessoa que possui TAB.

[...] o que ajuda muito é ter o apoio dos pais, que cuidam muito dela e cuidam das filhas dela. O que não deixa ela desistir totalmente é o apoio da familia. (F2)

É importante o acompanhamento da família. Eu vejo a diferença da minha outra irmã [pessoa que possui TAB], que está só ela e o marido. O marido não participa muito, não sabe como tratar tudo. (F1)

O papel da família em relação à pessoa que possui TAB é atribuído a estar presente, evitar o isolamento social incluindo a pessoa que tem TAB nas atividades diárias. A compreensão da condição de saúde proporciona à família um maior entendimento sobre as possíveis limitações que essa psicopatologia pode ocasionar na relação familiar.

Eu tento dar bastantes atividades, no sentido de: "vamos jantar fora, vamos almoçar fora”. Tento dar o melhor conforto possível. Desde questões materiais, até psicoemocionais. Eu tenho uma visão maior porque eu sei da doença, eu entendo como é a doença e tento ser o mais paciencioso possível. (F6)

A eficácia do tratamento está relacionada ao modo como se constitui a relação familiar. Nessa perspectiva, os familiares consideram que o tratamento medicamentoso é visto como algo importante, porém é complementar aos cuidados da família.

[...] o nosso outro irmão que não mora aqui não sabe a realidade. Para ele, ela [pessoa que possui TAB] faz o tratamento e está bem. Acha que é só a 
7 | Vasconcelos RO, Terra MG, Botega MSX, Soccol KLS, Girardon-Perlini NMO, Arnemann CT

medicação. Acha que não tem que ter atenção da família, que isso não influencia. E influencia bastante [...]. (F2)

Se ela tomar os remédios, for ao médico, chegar em casa e quem mora com ela a maltratar, não tiver consideração, não adianta o tratamento [...]. (F7)

Os familiares envolvidos diretamente com o cuidado almejam ter o apoio emocional e a ajuda dos outros integrantes da família. Entretanto, percebem que os familiares que não estão próximo, talvez pela pouca compreensão do diagnóstico, da instabilidade afetiva, dos sintomas e das mudanças de comportamento, tendem a se afastar, tornando difícil a relação familiar com a pessoa que possui TAB.

Tenho primas que não convivem tanto com ela [familiar que possui TAB]. Eu vejo que não têm a menor paciência, deixam mais de lado. Ignoram a família por causa dessa doença [...]. (F5)

[...] as minhas irmãs, eu acho que são um pouco negligentes. Poderiam estar vindo aqui em alguns momentos para visitar. Elas evitam entrar em contato porque ela tem a bipolaridade. Elas não sabem lidar com isso. E isso causa sofrimento. (F6)

Os familiares verbalizam sua preocupação com a atenção e o cuidado dispensado. Mencionam que o cuidado de forma excessiva, por receio de reinternações, poderia interferir no exercício da autonomia da pessoa que possui TAB.

Às vezes, de tanto cuidado que a gente tem, sufoca ela. Pode ser um cuidado excessivo, mas se a gente não tiver, sabemos as consequências em função das internações que ela teve [...]. (F2)

O fato de ter uma pessoa que possui TAB na família modifica significativamente o modo como os demais membros conduzem seu dia-a-dia. Os familiares procuram desenvolver atividades de confraternização, mas sentem-se inseguros e apreensivos quanto ao futuro, o cuidado, o tratamento e sobre os possíveis acontecimentos. 
A relação familiar com pessoas que possuem transtorno afetivo bipolar $\mid 8$

[...] a gente faz reuniões, faz um almoço junto, jantares. E sempre tem os momentos felizes. Dá para levar a vida assim. Mas não sei o que vai ser futuramente. Isso até, às vezes, assusta. (F5)

Essa categoria mostrou que a relação familiar com a pessoa que possui TAB, está relacionada com o modo como a família se organiza para proporcionar o cuidado. Assim, o conhecimento sobre a condição de saúde, os sintomas, o manejo e o tratamento, e as estratégias que elaboram têm influência direta sobre o prognóstico do transtorno. Observa-se que a família se reorganiza constantemente para manter inserido o seu familiar.

\section{Ser familiar de pessoa com transtorno afetivo bipolar: desafios no cotidiano das relações}

A relação familiar com a pessoa que possui $\mathrm{TAB}$ implica vivenciar situações que estão relacionadas aos sintomas da psicopatologia. Em alguns momentos essas circunstâncias levam a desafios e dificuldades, ocasionando para o cuidador um desgaste emocional e sobrecarga, que pode alterar negativamente no relacionamento com a família. As oscilações entre a fase maníaca, em que a heteroagressividade (agressão ao outro) é um comportamento apresentado, e os episódios de depressão, com algumas manifestações como os choros, são considerados um desafio no cotidiano da relação familiar:

Ela agride com a resposta que ela dá [...] às vezes, ela ofende sem se dar conta. Às vezes, eu fico chateada com o que ela me diz. Mas, depois eu deixo assim [...]. (F1)

[...] às vezes, ela estava bem e, às vezes, estava agressiva. Não queria socializar com as pessoas [...] As emoções dela são muito mais fortes, às vezes, ela está muito bem, feliz, brincando com as crianças e, às vezes, ela passa o tempo todo chorando. (F3) 
9 | Vasconcelos RO, Terra MG, Botega MSX, Soccol KLS, Girardon-Perlini NMO, Arnemann CT

O comportamento agressivo apresenta-se como uma barreira para a relação familiar, ocasionando situações, por vezes, insustentáveis de desavenças que, em consequência, levam ao isolamento e ao afastamento do convívio com os demais membros da família.

[...] até há pouco tempo, a gente sempre ficava do lado dele. Até que chegou a agredir o pai dele. Desde então, ele está afastado da família. (F7)

Dentre os desafios que se evidenciam na relação familiar, destacam-se as mudanças cíclicas de humor e a necessidade do familiar que realiza o cuidado de ter um espaço preservado, que lhe possibilite desenvolver atividades inerentes à sua vida particular.

[...] qualquer coisa que a gente fala, ela chora um monte, são muito extremas as coisas. Então, tem que dar alguma advertência: ela esbraveja, faz gestos bem exaltados e você tem que dar limites para que haja uma convivência benéfica para ambos. Eu também tenho meu espaço, tenho minha vida, e ela tem que respeitar isso. $(\mathrm{F} 6)$

A sobrecarga foi referida pelos familiares como uma circunstância vivenciada decorrente das modificações que acontecem em suas vidas, as quais ocasionam desgaste emocional, físico e mental. Os familiares, sobretudo, os cuidadores desejam, por vezes, se afastar do convívio sociofamiliar e desistir de cuidar. Os sentimentos de afeto e zelo são alguns motivos que os levam a manter a relação de cuidado.

[...] tem horas que a gente, quem cuida tem vontade de desistir, porque é muito cansativo. Não é só o bipolar que sofre, todo mundo que está envolvido sofre bastante. $\dot{A} s$ vezes, os familiares, os amigos estão mais sobrecarregados do que o bipolar porque tem que viver em função dele, tem que cuidar a medicação, tem que cuidar para ela não ter crise [...] E os pais, é difícil para eles. Porque ninguém quer ver um filho triste. Por isso, que eles não desistem. (F2) 
A relação familiar com pessoas que possuem transtorno afetivo bipolar $\mid 10$

[...] hoje em dia a nossa relação é boa, eu tento ignorar certas coisas e entendo que aquilo é da doença. Só que ao mesmo tempo, tem horas que eu não aguento. Então, eu acho que a relação só não é melhor realmente, porque essa é uma doença que machuca. [...] Ela não atinge só o sujeito que está sofrendo com aquilo, mas também quem está dentro de casa, os familiares em si [...]. (F4)

Entre os desafios em ter no núcleo familiar um integrante com TAB estão as mudanças de rotina no que tange a horários, frequentar escola e trabalho. Além das tarefas cotidianas, os familiares cuidadores precisam ainda desempenhar as atividades que seriam de responsabilidade da pessoa com transtorno, como os afazeres domésticos e os cuidados de outras pessoas, como irmãos menores.

[...] tinha dias que ela ia até de madrugada e a gente não conseguia dormir direito e no outro dia tinha aula de manhã. Tinha dias que ela estava em algum quadro depressivo, dormia o dia inteiro praticamente, e as coisas da casa ficavam. Eu tive que assumir esse papel de cuidar da casa e do meu irmão, que é mais novo [...]. (F4)

Devido ao meu horário de trabalho e as minhas atividades, não posso estar muito presente em casa. E quando eu estou presente ela quer muito a minha atenção. Isso é um problema porque eu tenho a minha vida. Eu tenho as minhas outras coisas para dar conta [...]. (F6)

Nos episódios de mania, a conduta impulsiva pode gerar riscos físicos e prejuízos morais para os familiares. Dentre as manifestações dessa fase do transtorno, foi evidenciada a compulsão por compras, ocasionando uma sobrecarga financeira para a família.

Às vezes, ela saí, comprava um monte de coisas. E, depois o meu pai não sabia nem como ia pagar. (F4) 
11 | Vasconcelos RO, Terra MG, Botega MSX, Soccol KLS, Girardon-Perlini NMO, Arnemann CT

Para os familiares, as alterações de humor, como a euforia e os sintomas psicóticos, relacionadas com as alucinações e os delírios, representam os maiores desafios na relação familiar com a pessoa que possui TAB.

O dia-a-dia é tranquilo [...]. Agora, tem algumas questões relativas à instabilidade do humor dela, que as coisas ficam um pouco complicadas [...] às vezes está muito eufórica, ela é uma pessoa que tem um temperamento muito difícil. (F6)

Só que foi piorando, porque começou a ter alucinações. Foi criando um universo para ela como se aquilo fosse real. (F4)

Em algumas situações, diante do esgotamento emocional, do sofrimento, da impotência e da falta de perspectiva de mudanças no modo de convivência, familiares que residem com a pessoa que possui $\mathrm{TAB}$ recorrem a alternativas que as possibilite afastar-se desse cenário, como uma maneira de preservarem a si e evitar um maior prejuízo na relação familiar.

[...] ela [filha] disse: eu saí de casa por causa dele [irmão que possui TAB]. Eu não queria sair, eu queria ficar na minha casa, eu não queria casar ainda. Eu fui porque eu não aguentava mais a vida com ele em casa [...]. (F7)

A não aceitação do diagnóstico pela pessoa que possui TAB torna difícil a adesão ao uso de psicofármacos. A resistência para utilizar os psicofármacos foi percebida pelos familiares como um desafio para o cuidado e convívio. Para a família, o retorno ou agravamento dos sintomas causados pela interrupção no uso dos medicamentos desestabiliza a dinâmica familiar, gerando frustração, desânimo e ansiedade.

[...] Ele não gosta que as pessoas contem que ele toma remédio. Não gosta que saibam que ele faz tratamento e que tem esse tipo de problema. Ele não aceita. (F7)

Quando ela começou a se sentir um pouco melhor ela simplesmente não tomou os remédios. Voltaram de novo todos os sintomas. Aquela luta de 
A relação familiar com pessoas que possuem transtorno afetivo bipolar $\mid 12$

novo e a gente não conseguia levar ela no médico, meu pai não sabia o que fazer [...]. (F4)

A relação familiar com a pessoa que possui TAB tende a ser difícil quando esse não adere ao uso correto dos psicofármacos. No entanto, o convívio pode ser harmonioso quando os sintomas estão controlados.

O dia-a-dia, quando ele estava conosco era muito bom, quando ele não estava em surto era bom. (F7)

Ser familiar de pessoa com TAB impõe no cotidiano familiar diversos desafios, nos quais podem estar presentes em alguns momentos as condutas heteroagressivas, as alterações de humor, os sintomas psicóticos e a sobrecarga emocional, física e financeira, a recusa em aderir ao uso de psicofármacos e a não aceitação do diagnóstico.

\section{Discussão}

A Reforma Psiquiátrica no Brasil, iniciada na década de 1970, tem como marco importante a Lei № 10.216/2001, que visa o alcance da recuperação das pessoas com sofrimento psíquico, que antes eram isoladas em manicômios, pela inserção na família, no trabalho e na comunidade. ${ }^{9}$ No entanto, nem sempre os familiares cuidadores têm cooperação e apoio necessário para suprir os aspectos instrumentais de funcionamento da família (aspectos rotineiros da vida diária como alimentar-se, preparar refeições, administrar medicações, dentre outros.

Para os familiares de pessoas com TAB esse é um aspecto importante, pois as mudanças na rotina diária assumem maior significado em razão desse transtorno em um membro da família. ${ }^{10}$ Isso está diretamente relacionado com os motivos que levam os familiares a 
procurarem as Associações, pois estas preenchem uma falta que existe na assistência às famílias dentro dos serviços de saúde mental, os quais nem sempre disponibilizam espaços para que os familiares compartilhem seus sentimentos e consigam conviver de uma forma menos árdua com as manifestações decorrentes dos transtornos mentais. ${ }^{3}$

O entendimento do diagnóstico e a busca por uma assistência especializada ao seu familiar ocorrem de modo progressivo, isto é, conforme eles se dão conta dos processos que estão vivenciando. Desse modo, em determinadas situações, os profissionais das equipes de saúde mental necessitam ofertar condições para que seja possível manter uma relação familiar saudável. A família é na maioria das vezes, o suporte de acolhimento para o esclarecimento das dúvidas que podem surgir em relação ao período que está sendo vivido pela pessoa que possui TAB.

Esse suporte pode ser por meio de um cuidado que proporcione o acesso da pessoa que possui TAB e sua família à Rede de Atenção Psicossocial (RAPS), promovendo a vinculação desses com os pontos de atenção, como os serviços de Atenção Básica em Saúde, Atenção Psicossocial Especializada, Atenção de Urgência e Emergência, Atenção Residencial de Caráter Transitório, entre outros..$^{9}$ Essa articulação deve constituir-se, portanto, de modo que possam ser expressas formas de pensar e agir em saúde mental, condizentes com a valorização das pessoas, seu contexto de vida, suas demandas e necessidades. ${ }^{11}$

Nesse sentido, se dá a importância da atuação do enfermeiro, que ao desenvolver ações terapêuticas e educativas junto aos familiares cuidadores podem contribuir efetivamente para a relação familiar com a pessoa que possui TAB. Trabalhar as dificuldades e promover o conhecimento sobre as medicações, o plano terapêutico, e tudo que envolve o tratamento e o diagnóstico de maneira geral, pode contribuir na redução de conflitos intrafamiliares. ${ }^{12}$ Bem como, cabe destacar a importância de pesquisas que possibilitem uma conexão com o cotidiano 
A relação familiar com pessoas que possuem transtorno afetivo bipolar $\mid 14$

das relações familiares, que levem em consideração as oscilações e as escolhas individuais, sem que isso seja passível de julgamentos. ${ }^{13}$

Em alguns momentos, há dificuldades na prestação de cuidados aos familiares que possuem $\mathrm{TAB}$, no que diz respeito à prestação de auxílio de forma adequada, principalmente em episódios de crise. ${ }^{14}$ Conforme evidenciado no presente estudo, a atenção dispensada à pessoa com TAB pode se tornar excessiva pelo receio de que ocorram novas internações psiquiátricas. Geralmente, a internação acontece quando há presença de sofrimento entre os familiares e estes não encontram outras soluções além desta. ${ }^{15}$

A não adesão aos psicofármacos interfere diretamente na relação familiar, podendo ocasionar alterações comportamentais e instabilidade à pessoa que possui TAB. Segundo uma pesquisa que avaliou a adesão a terapia medicamentosa por pessoas com transtorno de humor, a maioria dos participantes já havia se esquecido de fazer uso da medicação alguma vez. Porém, notar melhora ou piora de seu quadro não era um motivo para interrupção do tratamento. ${ }^{16} \mathrm{~A}$ percepção da melhora dos sintomas pela pessoa que possui TAB é considerado um fator para a suspensão da utilização dos psicofármacos.

No cotidiano dos familiares, alguns fatores são considerados desafiadores, pois fragilizam o núcleo familiar e as relações, demandando paciência e afeto. Por exemplo, as situações em que a pessoa com $\mathrm{TAB}$ apresenta um comportamento heteroagressivo, a não aceitação do diagnóstico, o desgaste físico, emocional e financeiro e o aumento das tarefas diárias, acarretando uma sobrecarga familiar.

O apoio à participação da família em grupos terapêuticos e a participação nas Associações pode ser uma estratégia de suporte, de modo a oportunizar um espaço de escuta, esclarecimentos, que amenize o sofrimento diante das demandas de cuidado. Para os profissionais, estes espaços propiciam conhecer melhor o contexto e realidade familiar na qual 
15 | Vasconcelos RO, Terra MG, Botega MSX, Soccol KLS, Girardon-Perlini NMO, Arnemann CT

se encontram inseridos, e assim fornecer apoio adequado, tendo como foco as necessidades das pessoas em sofrimento psíquico e suas famílias. ${ }^{17}$

Fundamentado nos ideais do paradigma psicossocial, os resultados do presente estudo mostram a importância do papel desempenhado pela família no cuidado à pessoa que possui TAB. Também, aponta a necessidade de um olhar diferenciado e suporte dos profissionais da saúde para os familiares.

\section{Considerações finais}

A relação familiar com a pessoa que possui $T A B$ pode ser positiva, influenciada pela existência de suporte da família no cuidado. Entretanto, perpassa momentos difíceis, relacionados à apresentação de sintomas exacerbados da psicopatologia, que podem estar vinculados à adesão ao uso de psicofármacos e à aceitação do diagnóstico pelo familiar que possui TAB. Há desafios a serem superados no que concerne à compreensão da família para o cuidado e ao entendimento do diagnóstico em sua complexidade, tanto pelos familiares, quanto pelas pessoas com TAB.

Como reflexo do atual modelo de atenção em saúde mental, os familiares percebem o território e a família como principal lugar de cuidado. Não mencionando o hospital como primeira opção para o cuidado, mas o núcleo familiar que quando bem articulado apresenta potencial para evitar as reinternações.

Enfatiza-se que os familiares apontaram as dificuldades na relação familiar, entretanto não mencionaram se possuem ou quem realiza o suporte para amenizar a sobrecarga. Portanto, por meio dos resultados deste estudo, ressalta-se a importância do acolhimento aos familiares nos serviços de saúde, objetivando uma maior compreensão acerca de suas necessidades e 
A relação familiar com pessoas que possuem transtorno afetivo bipolar $\mid 16$

percepções em momentos de escuta para a implementação de estratégias assertivas de melhoria da atenção pela equipe de saúde.

Como limitações desta pesquisa, tem-se a participação de familiares membros de apenas uma Associação específica, não abrangendo outros cenários de assistência à saúde mental. A realização de mais investigações como esta poderá apontar outros aspectos referentes à relação familiar com pessoas que possuem TAB, aqui não evidenciados.

\section{Referências}

1. Muniz MP, Tavares CMM, Abrahão AL, Souza AC. A assistência de enfermagem em tempos de reforma psiquiátrica. Rev Port Enferm Saúde Mental [Internet]. 2015 [acesso em 2018 nov 01];13:61-5. Disponível em: http://www.scielo.mec.pt/scielo.php?script=sci_arttext\&pid=S1647-21602015000200008

2. Fernandes MA, Sousa KHJF, Andrade PCA, Carvalho LCS, Pereira DBD, Silva BJM. Transtorno afetivo bipolar, episódio atual maníaco com sintomas psicóticos e o cuidar em enfermagem. Rev Enferm UFPE On Line [Internet]. 2016 [acesso em 2018 nov 01];10(2):669-74. Disponível em: https://periodicos.ufpe.br/revistas/revistaenfermagem/article/view/11004

3. Borges TT, Rezende MGC, Nunes CR. Assistência de enfermagem: implicações na adesão ao tratamento de portadores de transtorno afetivo bipolar. Múltiplos Acessos [Internet]. 2017 [acesso em 2017 jul 18];1(1):34-46. Disponível em: http://www.multiplosacessos.com/multaccess/index.php/multaccess/article/view/5

4. Gomes ID, Lopes MAP, Monteiro MCPD, Basto ML, Oliveira CS, Botelho MAR, et al. Grupo de suporte à família da pessoa com doença mental grave: um porto de abrigo na adversidade. In: Anais do $6^{\circ}$ Congresso Ibero-Americano em Investigação Qualitativa (CIAIQ 2017); 2017 jul 14-16; Salamanca (Espanha). Salamanca: CIAIQ; 2017 [acesso em 2017 ago 14]. Disponível em: http://proceedings.ciaiq.org/index.php/ciaiq2017/article/view/1300/1259

5. Martins PPS, Guanaes-Lorenzi C. Participação da família no tratamento em saúde mental como prática no cotidiano do serviço. Psicol Teor Pesqui [Internet]. 2017 [acesso em 2018 jul 27];32(4). Disponível em: http:/www.scielo.br/scielo.php?script=sci_arttext\&pid=S010237722016000400216\&lng=en\&nrm=iso doi: 10.1590/0102.3772e324216

6. Viegas SMF, Penna CMM. As dimensões da integralidade no cuidado em saúde no cotidiano da Estratégia Saúde da Família no Vale do Jequitinhonha, MG, Brasil. Interface (Botucatu) [Internet]. 2015 
[acesso em 2018 set 08];19(55):1089-100. Disponível em: http://www.scielo.br/pdf/icse/v19n55/1807-5762icse-1807-576220140275.pdf

7. Minayo MCS. O desafio do conhecimento: pesquisa qualitativa em saúde. São Paulo (SP): Hucitec; 2014.

8. Bardin L. Análise de Conteúdo. São Paulo (SP): Edições 70; 2011.

9. Brasil. Presidência da República. Lei no 10.216, de 06 de abril de 2001. Dispõe sobre a proteção e os direitos das pessoas portadoras de transtornos mentais e redireciona o modelo assistencial em saúde mental [Internet]. 2011 [acesso em 2018 jun 12]. Disponível em: http://www.planalto.gov.br/ccivil_03/Leis/LEIS_2001/L10216.htm

10. Ramos AC, Calais SL, Zotesso MC. Convivência do familiar cuidador junto a pessoa com transtorno mental. Contextos Clín [Internet]. 2019 jan-abr [acesso em 2019 abr 13];12(1):282-302. Disponível em: http://www.revistas.unisinos.br/index.php/contextosclinicos/article/view/ctc.2019.121.12/60746848

11. Jorge MSB, Diniz AM, Lima LL, Penha JC. Apoio matricial, projeto terapêutico singular e produção do cuidado em saúde mental. Texto \& Contexto Enferm [Internet]. 2015 mar [acesso em 2018 jun 12];24(1):112-20. Disponível em: http://www.scielo.br/pdf/tce/v24n1/pt_0104-0707-tce-24-01-00112.pdf

12. Xavier MST, Terra MG, Silva CTS, Souto VT, Mostardeiro SCTS, Vasconcelos RO. A utilização de psicofármacos em indivíduos com transtorno mental em acompanhamento ambulatorial. Enferm Glob [Internet]. 2014 out [acesso em 2017 maio 15];13(36):114-25. Disponível em: http://revistas.um.es/eglobal/article/view/201121/165631

13. Gama CAP, Campos RTO, Ferrer AL. Saúde mental vulnerabilidade social: a direção do tratamento. Rev Latinoam Psicopatol Fundam [Internet]. 2014 [acesso em 2015 jun 10];17(1):69-84. Disponível em: http://www.scielo.br/scielo.php?script=sci_arttext\&pid=S1415-47142014000100006

14. Kebbe LM, Rôse LBR, Fiorati RC, Carretta RYD. Cuidando do familiar com transtorno mental: desafios percebidos pelos cuidadores sobre as tarefas de cuidar. Saúde Debate [Internet]. 2014 set [acesso em 2019 abr 13];38(102):494-505. Disponível em: https:/www.scielosp.org/pdf/sdeb/2014.v38n102/494$505 / \mathrm{pt}$

15. Xavier MS, Terra MG, Schimith MD, Leite MT, Kruse MHL, Arnemann CT. Compreensão de enfermeiras atuantes em saúde mental sobre a internação compulsória e involuntária. Esc Anna Nery Rev Enferm [Internet]. 2017 [acesso em 2017 maio 15];21(3):e20160262. Disponível em: http://www.scielo.br/pdf/ean/v21n3/1414-8145-ean-2177-9465-EAN-2016-0262.pdf

16. Freire EC, Feijó CFC, Fonteles MMF, Sá JSE, Carvalho TP. Adesão ao tratamento medicamentoso em usuários com transtorno do humor de centro de atenção psicossocial do nordeste do Brasil. Rev Ciênc Farm Básica Apl [Internet]. 2014 [acesso em 2017 jul 12];34(4):565-70. Disponível em: http://200.145.71.150/seer/index.php/Cien_Farm/article/viewArticle/2641 
17. Loro MM, Roever E, Kolankiewicz ACB, Bernat AN, Herr GEG, Rosanelli CDLP. Percepção de profissionais de enfermagem frente ao atendimento de pacientes com transtorno afetivo bipolar. Rev Contexto Saúde [Internet]. 2013 [acesso em 2017 jul 12];11(20):1171-6. Disponível em: https://revistas.unijui.edu.br/index.php/contextoesaude/article/view/1765/1469

\section{Autor correspondente}

Raíssa Ottes Vasconcelos

E-mail: raissa_07@msn.com

Endereço: Av. Doutor Enéas Carvalho de Aguiar n 419, bairro Cerqueira César, São Paulo, SP, Brasil.

CEP: 05403-000

\section{Contribuições de Autoria}

\section{1 - Raíssa Ottes Vasconcelos}

Concepção e planejamento do projeto de pesquisa; obtenção ou análise e interpretação dos dados e redação e revisão crítica.

\section{2 - Marlene Gomes Terra}

Concepção e planejamento do projeto de pesquisa; interpretação dos dados e revisão crítica.

\section{3 - Mariane da Silva Xavier Botega}

Concepção e planejamento do projeto de pesquisa; interpretação dos dados e redação e revisão crítica.

\section{4 - Keity Laís Siepmann Soccol}

Interpretação dos dados e redação e revisão crítica.

\section{5- Nara Marilene Oliveira Girardon-Perlini}

Redação e revisão crítica.

6 - Cristiane Trivisiol Arnemann

Redação e revisão crítica.

\section{Como citar este artigo}

Vasconcelos RO, Terra MG, Botega MSX, Soccol KLS, Girardon-Perlini NMO, Arnemann CT. A relação familiar com pessoas que possuem transtorno afetivo bipolar. Rev. Enferm. UFSM. 2020 [Acesso em: Anos Mês Dia]; vol.10 e30: 1-18. DOI:https://doi.org/10.5902/2179769237694 